\title{
Quantitation of Lanosterol and Its Major Metabolite FF-MAS in an Inhibition Assay of CYP51 by Azoles with Atmospheric Pressure Photoionization Based LC-MS/MS
}

\author{
Eva R. Trösken, Ellen Straube, Werner K. Lutz, and Wolfgang Völkel \\ Department of Toxicology, University of Würzburg, Würzburg, Germany \\ Christopher Patten \\ BD-Gentest, BD Biosciences Discovery Labware, Woburn, Massachusetts, USA
}

\begin{abstract}
Azoles affect the steroid balance in all biological systems and may therefore be called endocrine disrupters. Lanosterol $14 \alpha$-demethylase (CYP51) is an enzyme inhibited by azoles. Only few data have been reported showing their inhibitory potency since an assay in an in vitro system is not available so far. In the present work an inhibition assay using human recombinant CYP51, coexpressed with human P450 oxido-reductase by the baculovirus/insect cell expression system, and LC-MS/MS as analytical method is described. Atmospheric pressure photoionization (APPI) and atmospheric pressure chemical ionization (APCI) sources were used with a triple quadrupole mass spectrometer to compare quantitation of lanosterol (substrate) and 4,4-dimethyl-5 $\alpha$-cholesta-8,14,24-triene-3 $\beta$-ol (FF-MAS) (product of CYP51) with $\mathrm{d}_{6}-2,2,3,4,4,6$-cholesterol $\left(\mathrm{d}_{6}\right.$-cholesterol) as internal standard. Optimization of analytical parameters resulted in a LC-APPI-MS/MS method with a LOQ of $10 \mathrm{pg}$ on column for FF-MAS. The sensitivity of the method (LOD $0.5 \mathrm{ng} / \mathrm{ml}$ ) makes it possible to analyze supernatants of inhibition experiments after precipitation of proteins by isopropanol without any sample enrichment. The coefficient of variation of the analytical method was $<20 \%$ ( $n=$ 5) for FF-MAS, lanosterol and $\mathrm{d}_{6}$-cholesterol. The external calibration curve was linear from 1 to $10,000 \mathrm{ng} / \mathrm{ml}$ with $\mathrm{R}^{2} \geq 0.999$ and an accuracy of $94-115 \%$. Compared with APCI, APPI provides a ten- to 500 -fold increase in sensitivity for the analytes in this study. $\mathrm{IC}_{50}$ values of epoxiconazole and miconazole - two widely used azole fungicides used in agriculture and in human medicine, respectively-were $1.95 \mu \mathrm{M}$ and $0.057 \mu \mathrm{M}$. (J Am Soc Mass Spectrom 2004, 15, 1216-1221) @ 2004 American Society for Mass Spectrometry
\end{abstract}

A zoles (imidazoles and triazoles) exhibit an antifungal activity and are widely used as fungicides in agriculture as antimycotic agents but also as medical drugs for tumor chemotherapy. These different applications have been discussed for the observed increase of resistance of human fungal infections against azole treatment. Furthermore, azoles are suggested as a new group of endocrine active agents disturbing the biosynthesis of steroids by inhibition of cytochrome P450 enzymes like aromatase (CYP19) [1] and lanosterol $14 \alpha$-demethylase (CYP51).

The antifungal activity of azoles is based on the inhibition of sterol biosynthesis, particularly catalyzed by lanosterol $14 \alpha$-demethylase (CYP51), a widely distributed and highly conserved cytochrome P450-depen-

Published online July 2, 2004

Address reprint requests to Dr. W. Völkel, Department of Toxicology, University of Würzburg, Versbacher Strasse 9, Würzburg 97078, Germany. E-mail: voelkel@toxi.uni-wuerzburg.de dent monooxygenase [2]. Inhibition results in a decrease of ergosterol and increase of chitin which are critical components of the fungal cell wall [3]. In mammals CYP51 catalyzes the oxidative demethylation of lanosterol (Scheme 1). The resulting sterols in testis, sperm, and follicle are named meiosis activating sterols (MAS) [4, 5]. Therefore the inhibition of CYP51 by azoles may also influence the endocrine balance in mammals as previously suggested [6].

No assay for testing the inhibitory effect of azoles to CYP51 comparable to that of CYP19 is available. Such a method is necessary to test azoles applied as fungicides agriculturally or in human medicine for their inhibitory potency of CYP51. It would further be useful for the development of new substances, designed to inhibit specifically only CYP51.

Lanosterol and its metabolites were predominantly quantitated directly or after derivatization by gas chromatography mass spectrometry (GC-MS) [7, 8]. If amounts of about $1 \mathrm{ng}$ of each steroid were available, 


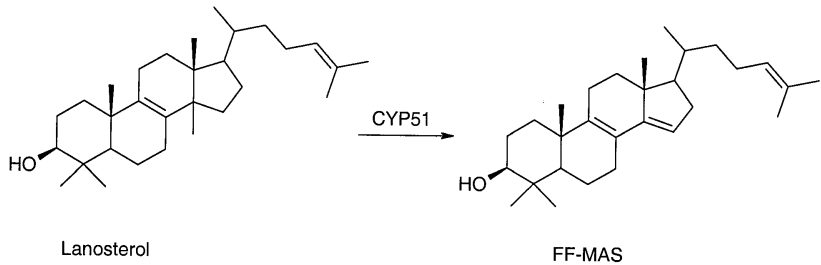

Scheme 1. Demethylation of lanosterol to FF-MAS catalyzed by CYP51.

lanosterol and FF-MAS could be separated by reversed phase high performance liquid chromatography (HPLC) and detected using a diode array detector [9]. The detection of steroids like cholesterol and cholesterol oxides by HPLC mass spectrometry (HPLC-MS) using an atmospheric pressure chemical ionization (APCI) source are published [10]. APCI has to be used instead of electrospray ionization (ESI) since steroids are too lipophilic and exhibit no moieties for protonation or deprotonation processes typical for ESI. The distinction of ergosterol from lanosterol by APCI and tandem mass spectrometry was reported with a limit of detection in the low $\mathrm{ng} / \mathrm{ml}$ range [11]. Here we present a LCMS/MS method using an atmospheric pressure photoionization source for quantitation of lanosterol and FF-MAS in the low $\mathrm{ng} / \mathrm{ml}$ range. It was tested in inhibition experiments of azoles with a human recombinant CYP51 enzyme. To our knowledge, this is the first time that an assay based on a human recombinant CYP51 enzyme combined with an APPI-MS/MS method is used for quantitation of CYP51 inhibition by azoles.

\section{Materials and Methods}

\section{Chemicals and Reagents}

Epoxiconazole was a kind gift from the Swiss Federal Research Station, Wädenswil, Switzerland. 4,4-Dimethyl- $5 \alpha$-cholesta-8,14,24-triene-3 $\beta$-ol (FF-MAS) was a kind gift from NovoNordisk (Gentofte, Denmark). HPLC grade water was from Roth (Karlsruhe, Germany). All other chemicals were from Sigma/Fluka (Taufkirchen, Germany). All solvents used were HPLC grade or better.

Human lanosterol 14 $\alpha$-demethylase (CYP51, Accession No. U23942) coexpressed with human P450 reductase (baculovirus/insect cell-expressed) was constructed using vectors and viral DNA from PharMingen (San Diego, CA) according to the manufacturer's instructions. Enzyme expression was carried out in spinner flasks of BTI-TN-5B1-4 insect cells. Infection time was for $48 \mathrm{~h}$. Membrane fraction from insect cells was prepared according to standard methods with slight modification [12].

\section{Inhibition Assay}

Stock solutions of lanosterol $(1 \mathrm{mM})$ and Triton X-100 $(16 \mathrm{mg} / \mathrm{ml})$ were prepared in isopropanol. Stock solutions and dilution series of azoles were prepared in ethanol.

Lanosterol $(11.9 \mu \mathrm{M})$ was incubated in $0.1 \mathrm{M}$ potassium phosphate buffer $(\mathrm{pH} 7.4)$ containing $1.1 \mathrm{mM}$ $\mathrm{NADP}^{+}, 2.8 \mathrm{mM}$ glucose-6-phosphate, $0.34 \mathrm{U} / \mathrm{ml}$ glucose-6-phosphate dehydrogenase, $2.8 \mathrm{mM}$ magnesium chloride, $1 \mu \mathrm{l}$ of azole dilution and $2 \mu \mathrm{l}$ of the Triton X-100 stock solution in a total volume of $84 \mu \mathrm{l}$ in all experiments. The reaction mixture was preincubated for $5 \mathrm{~min}$ at $37{ }^{\circ} \mathrm{C}$ and the reaction was started by addition of the enzyme (0.1 $\mu \mathrm{M}$ CYP51). After $40 \mathrm{~min}$ at $37{ }^{\circ} \mathrm{C} 80 \mu \mathrm{l}$ of isopropanol containing internal standard $(5 \mu \mathrm{M})$ were added to stop the reaction. Protein was removed by centrifugation at $15,000 \mathrm{~g}$ for $5 \mathrm{~min}$. The supernatant was analyzed by LC-MS/MS.

\section{Optimization of Mass Spectrometry Methods}

Each method (LC-APCI-MS/MS, LC-APPI-MS/MS) was optimized separately with respect to sensitivity, analyte identification, and quantitative measurement. Infusion experiments to examine ionization and fragmentation patterns of the analytes were carried out with both sources. A syringe pump (Single Syringe Pump 11, Harvard Apparatus Inc., Holliston, MA) was used to provide a constant analyte infusion $(300 \mu \mathrm{l} / \mathrm{min})$ into the LC eluent via a T-connection. Analyte concentrations were chosen in the range of 5-100 ng/ $\mu \mathrm{l}$ to obtain a constant signal in the Q1 scan mode. Basic source and MS parameters such as declustering potential (DP), focussing potential (FP), collision energy (CE), and exit potential (CXP) were optimized using the quantitative optimization function of Analyst version 1.3.1. (Applied Biosystems, Darmstadt, Germany).

\section{Quantitation}

To quantify lanosterol, FF-MAS and $\mathrm{d}_{6}$-cholesterol $10 \mu \mathrm{l}$ of the supernatants were injected on a Symmetry Shield $\mathrm{C}_{8}$ HPLC column $(3.0 \mathrm{~mm} \times 150 \mathrm{~mm} ; 5 \mu \mathrm{m}$; Waters, Eschborn, Germany) using an Agilent 1100 (Waldbronn, Germany) autosampler and an Agilent 1100 HPLC-pump. The samples were separated by gradient elution with water (Solvent A) and $\mathrm{MeOH}$ (Solvent B) using the following conditions: $50 \%$ A isocratic for 1 min, linear to $2 \% \mathrm{~A}$ within $1 \mathrm{~min}$, and isocratic for $8 \mathrm{~min}$ at $2 \%$ A with a flow rate of $600 \mu \mathrm{l} / \mathrm{min}$. For APPI measurements toluene was used as dopant with a flow rate of $42 \mu \mathrm{l} / \mathrm{min}$. The dopant was delivered to the APPI source with a syringe pump and a $50 \mathrm{ml}$ gastight glass syringe (Hamilton Company, Reno, NV). The HPLC system was directly coupled to a triple stage quadrupole mass spectrometer (API 3000, Applied Biosystems) equipped with an atmospheric pressure chemical ionization or an atmospheric pressure photoioniza- 
tion source. Analytes were detected in the positive ion mode at a vaporizer temperature of $400{ }^{\circ} \mathrm{C}$. For APCI a needle current of 3 and for APPI a source voltage (IS) of 2000 was applied. Spectral data were recorded with $\mathrm{N}_{2}$ as collision gas $(\mathrm{CAD}=4)$ in the multiple reaction monitoring (MRM) mode with a dwell time of $500 \mathrm{~ms}$ for each transition monitoring the following MS/MS ion-transitions.

\section{MS/MS-Transitions, Declustering Potential and Collision Energy Used}

\begin{tabular}{|c|c|c|c|}
\hline Transition & Compound & DP [V] & CE [V] \\
\hline \multicolumn{4}{|c|}{$\left[\mathrm{M}+\mathrm{H}-\mathrm{H}_{2} \mathrm{O}\right]^{+} \rightarrow$} \\
\hline $409.5 \rightarrow 109.1$ & Lanosterol (quantifier) & 41 & 43 \\
\hline $409.5 \rightarrow 95.3$ & Lanosterol (qualifier) & 41 & 51 \\
\hline $375.4 \rightarrow 167.5$ & $\begin{array}{l}\mathrm{d}_{6} \text {-Cholesterol (quantifier, } \\
\text { internal standard) }\end{array}$ & 36 & 31 \\
\hline $375.4 \rightarrow 95.2$ & $\begin{array}{l}\mathrm{d}_{6} \text {-Cholesterol (qualifier, } \\
\text { internal standard) }\end{array}$ & 36 & 55 \\
\hline $393.5 \rightarrow 68.9$ & FF-MAS (quantifier) & 46 & 55 \\
\hline $393.5 \rightarrow 55.2$ & FF-MAS (qualifier) & 46 & 63 \\
\hline
\end{tabular}

Quantitation of FF-MAS was based on calibration curves obtained after addition of known amounts of FF-MAS $(1-10,000 \mathrm{ng} / \mathrm{ml})$ to incubation samples containing heat-deactivated CYP51. Calibration curves were calculated from seven duplicate data points using Analyst 1.3.1.

\section{Data Evaluation}

The concentration range to be tested in the main experiment was defined in a dose-finding study with inhibitor concentration steps of factors of ten.

For the main experiment, at least seven logarithmically spaced concentrations were used, with the expected $\mathrm{IC}_{50}$ at the median. Dose responses were run in duplicates. A full analytical method for the quantitation of amounts of FF-MAS produced for the described inhibition studies was developed.

The area of FF-MAS corrected by the internal standard (relative area) was plotted against the log (base 10) of the concentration of azole. Four parameters were estimated by fitting the two replicate area data sets to a probit curve: The FF-MAS relative area at azole concentration 0 and $\infty$, the relative area at half maximum inhibition, and the slope of the probit curve. Statistical analysis was performed by a nonlinear mixed-effects model fit by maximum likelihood run on the statistics software " $R$ ". A random error was attributed to the FF-MAS relative area at azole concentration 0 , to account for differences between replicates for the extrapolated null measurement.

$\mathrm{R}$ is a language and environment for statistical computing and graphics. It is available as Free Software under the terms of the Free Software Foundation's GNU General Public License in source code form. It compiles and runs on a wide variety of UNIX platforms

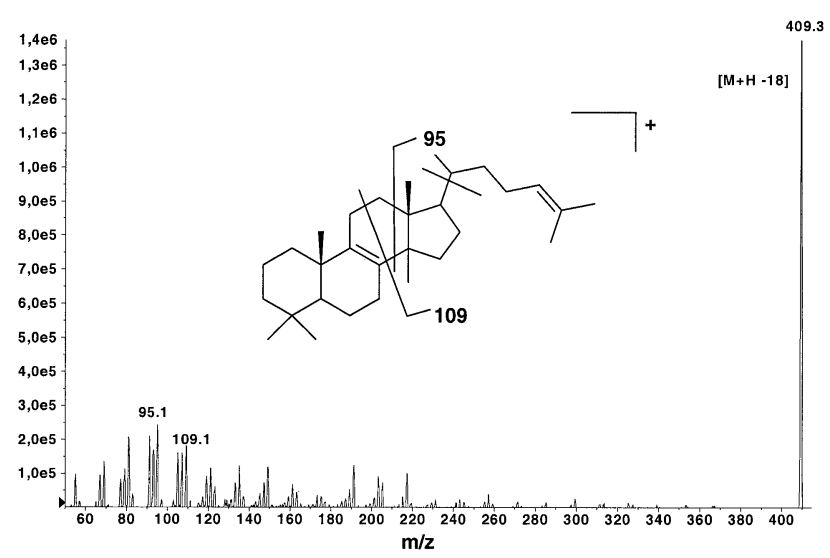

Figure 1. Product ion spectrum of lanosterol.

and similar systems (including FreeBSD and Linux), Windows, and MacOS. Information on download is available at http://www.r-project.org.

\section{Results}

\section{Characterization of CYP51}

Membrane fractions of baculovirus expressed CYP51 were tested for the conversion of $\left[{ }^{3} \mathrm{H}\right]$-lanosterol to FF-MAS using previously described methods [13]. The turnover number using $15 \mu \mathrm{M}$ lanosterol was $0.9 \mathrm{pmol} /$ $\mathrm{min} / \mathrm{pmol} \mathrm{P} 450$.

\section{Identification and Quantitation of FF-MAS}

Due to their lipophilic character the ionization of lanosterol, FF-MAS and $d_{6}$-cholesterol was performed with atmospheric pressure chemical ionization or atmospheric pressure photoionization. Collision-induced dissociation (CID) of $\left[\mathrm{M}+\mathrm{H}^{+}-\mathrm{H}_{2} \mathrm{O}\right]^{+}$of all compounds provided a number of characteristic fragmentations in spite of the low collision energies used (Figures 1, 2, and 3). For quantitation of FF-MAS in biological solutions, a method based on HPLC separa-

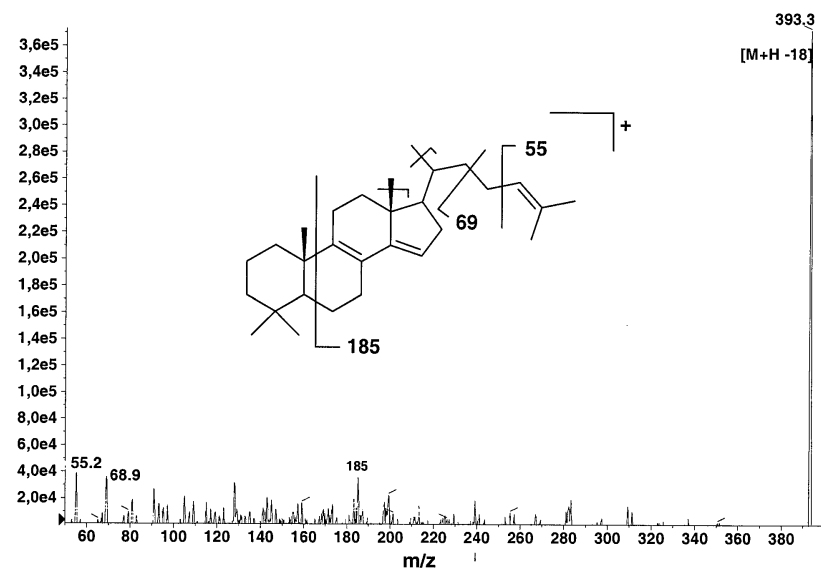

Figure 2. Product ion spectrum of FF-MAS. 


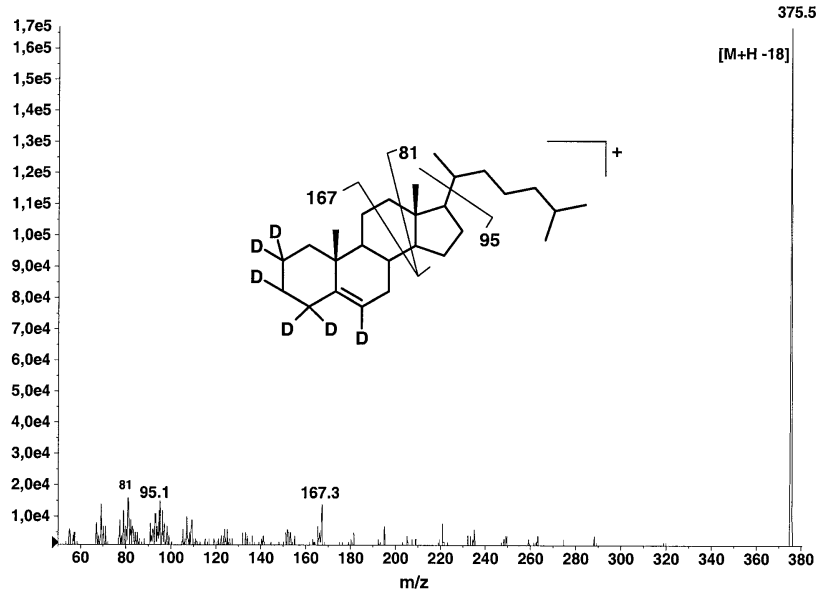

Figure 3. Product ion spectrum of $\mathrm{d}_{6}$-cholesterol.

tion and multiple reaction monitoring mode was developed with the most intensive product ions $\mathrm{m} / \mathrm{z}$ 68.9 [M $\left.-\mathrm{C}_{24} \mathrm{H}_{37} \mathrm{O}\right]^{+}$and $m / z 55.2\left[\mathrm{M}-\mathrm{C}_{25} \mathrm{H}_{39}\right]^{+}$for FF-MAS and $m / z 167.5\left[\mathrm{M}-\mathrm{C}_{15} \mathrm{H}_{28}\right]^{+}$for $\mathrm{d}_{6}$-cholesterol used as internal standard. Calibration curves were linear in the range of $1-10,000 \mathrm{ng} / \mathrm{ml}$ with $\mathrm{R}^{2} \geq 0.999$. The accuracy for FF-MAS in incubation solution were within $100 \pm$ $20 \%$ for $n=5$ analyses of $10 \mathrm{ng} / \mathrm{ml}$ (Table 1 ).

With the APPI source, the limit of quantitation (LOQ) could be reduced by a factor of 10 for lanosterol and FF-MAS ( $5 \mathrm{ng} / \mathrm{ml}$ and $1 \mathrm{ng} / \mathrm{ml}$ respectively) and by a factor of 500 for $\mathrm{d}_{6}$-cholesterol $(0.1 \mathrm{ng} / \mathrm{ml})$ compared to APCI (Table 1). Thus, only very low amounts of about 8 pmol of the recombinant enzyme are required.

\section{Inhibition of CYP51 by Azoles}

Inhibition studies were carried out with two azoles. Epoxiconazole is used as a fungicide, miconazole is used in human medicine to treat fungal infections e.g.,

Table 1. Analytical data of 3 steroids applying LC-APCI-MS/ MS or LC-APPI-MS/MS

\begin{tabular}{|c|c|c|c|}
\hline & & $\mathrm{APCl}$ & APPI \\
\hline \multirow[t]{6}{*}{ Lanosterol } & LOD [ng/ml] & 10 & 0.5 \\
\hline & LOQ [ng/ml] & 50 & 5 \\
\hline & dynamic range $[\mathrm{ng} / \mathrm{ml}]$ & 50-1000 & $5-10000$ \\
\hline & accuracy & $80-120 \%$ & $85-100 \%$ \\
\hline & precision $(10 \times$ LOQ $)$ & $16 \%$ & $4 \%$ \\
\hline & regression factor & 0.975 & 0.999 \\
\hline \multirow[t]{6}{*}{ FF-MAS } & LOD [ng/ml] & 5 & 0.5 \\
\hline & LOQ [ng/ml] & 10 & 1 \\
\hline & dynamic range $[\mathrm{ng} / \mathrm{ml}]$ & $10-1000$ & $1-10000$ \\
\hline & accuracy $(10 \times$ LOQ $)$ & $80-100 \%$ & $94-115 \%$ \\
\hline & precision $(10 \times$ LOQ $)$ & $14 \%$ & $8 \%$ \\
\hline & regression factor & 0.998 & 0.999 \\
\hline \multirow[t]{6}{*}{$\mathrm{d}_{6}$-Cholesterol } & LOD [ng/ml] & n.d. & n.d. \\
\hline & LOQ [ng/ml] & 50 & 0.1 \\
\hline & dynamic range $[\mathrm{ng} / \mathrm{ml}]$ & $50-5000$ & $0.1-5000$ \\
\hline & accuracy $(10 \times$ LOQ $)$ & $91-119 \%$ & $81-111 \%$ \\
\hline & precision $(10 \times$ LOQ $)$ & $10 \%$ & $7 \%$ \\
\hline & regression factor & 0.999 & 0.998 \\
\hline
\end{tabular}

of the skin or of the intestine. For epoxiconazole an $\mathrm{IC}_{50}$ value of $1.95 \mu \mathrm{M}$ (factor 1.51 as geometric standard error), and for miconazole an $\mathrm{IC}_{50}$ value of $0.057 \mu \mathrm{M}$ (geometric standard error $=1.24$ ) were calculated.

\section{Discussion}

The described inhibition assay uses conditions that were optimized for the comparison of different inhibitors. Substrate concentration was chosen to achieve high turn-over rates for lanosterol under optimal incubation conditions for CYP51 activity. Since lanosterol solubility is limited in aqueous systems and CYP51 activity decreases with increasing amounts of organic solvents, a compromise had to be found. More than optimal amounts of organic solvent were needed to keep lanosterol reproducibly in solution. To limit the required amount of alcohol, suboptimal lanosterol concentrations were used. This resulted in reproducible turnover rates below $\mathrm{K}_{\mathrm{m}}$, but required a highly sensitive analytical method to detect FF-MAS as the product of the enzymatic reaction.

Neutral sterols like lanosterol and FF-MAS were typically identified and quantitated in biological samples by GC-MS with or without derivatization [14, 15]. The use of GC-MS requires a time consuming sample work up to get volatile analytes and solvents. This is especially complicated for samples in an aqueous matrix. Therefore, and because of the importance of sterols in medical applications, LC-MS based methods have to be developed to analyze sterols in biological samples. The same holds for the analysis of environmental water samples collected near farmlands and sewage plants, where sterols are discussed as important endocrine disrupters threatening the ecosystems [16].

The disadvantage of LC-MS for the analysis of neutral sterols is the poor ionization efficiency by electrospray ionization. Lanosterol, FF-MAS, and $\mathrm{d}_{6}$-cholesterol could not be ionized at concentrations below 100 $\mathrm{ng} / \mu \mathrm{l}$ (data not shown). To improve ion formation in the ESI mode analytes have to be derivatized i.e., with electrophoric labels like pentafluorobenzyl chloride which generally requires sample work up comparable to the GC-MS procedure. Another possibility is the use of sources which allow the ionization of more lipophilic compounds like the atmospheric pressure chemical ionization (APCI) source [17, 18].

Previously, the atmospheric pressure photoionization source independently developed by Bruins and Syage, was used for ionization of corticosteroids by Greig et al. showing a higher sensitivity compared to ESI and APCI [19, 20]. Greig et al. used a Fourier transform ion cyclotron mass spectrometer (FTICRMS) which allows very sensitive analyses in the high resolution mode [19].

Another possibility to get highest sensitivity with a more common mass selective detector is the use of a triple quadrupole mass spectrometer. Collision induced dissociation (CID) creates characteristic fragments that can be analyzed in the third quadrupole. The product 
ion spectra presented in Figure 1-3 are not very typical for CID spectra. Usually, few characteristic fragment ions are produced by lower energies compared to electron impact (EI) spectra. In the case of steroids the fragment pattern is very similar to EI or to particle beam spectra of sterols as published by Byskov et al. [21]. CID spectra similar to ours have previously been published for $6 \beta-\mathrm{OH}$-hydrocortisone and testosterone [22, 23]. The fragments of the sterols presented in Figure 1-3 are calculated as described for particle beam spectra of FF-MAS and lanosterol where a side chain fragmentation was observed [21]. The product ion spectrum of ergosterol also shows a prominent $\mathrm{m} / \mathrm{z} 69$ identified as $\left[\left(\mathrm{CH}_{3}\right)_{2} \mathrm{CHCH}=\mathrm{CH}\right]^{+}$generated by $\mathrm{CID}$ of the side chain [24]. In addition, for sterols like estrone or testosterone, a fragmentation in the C-ring of the steroid has been reported after collision induced dissociation as suggested in Figures 1 and 3 [17, 25].

For the described application highest ionization efficiency is achieved by the APPI source. In combination with the use of the multiple reaction monitoring (MRM) scan mode, which provides very low noise levels, the detection and quantitation in the low $\mathrm{ng} / \mathrm{ml}$ range (0.1-5) is possible. These results are comparable to the electron capture (EC) derivatization procedure for estrone [17]. For lanosterol, FF-MAS and $\mathrm{d}_{6}$-cholesterol the use of the APPI source instead of the APCI source resulted in a 10to 500-fold lower LOD and LOQ (Table 1). Greig et al. also reported a better signal to noise using APPI versus APCI but did not provide quantitative data [19].

In contrast to FTICRMS, the APPI-MRM method is useful for quantitation in a wide dynamic range (Table 1). Compared to EC-APCI, only a simple sample work up with a precipitation of proteins by centrifugation is necessary. This cleaning step is efficient for highest sensitivity, reproducibility and accuracy better than $100 \pm 20 \%$ at LOQ for all analytes tested so far. The measurements with the APPI source were more precise than those with APCI using identical chromatographic conditions. This might be attributed to the fact, that ionization efficiency is higher for APPI. Ionization efficiency is defined as the relative amount of ions formed in comparison to the total amount of analyte present in the source. We assume that the average run-to-run difference in ionization efficiency per amount of analyte present is equal/comparable for both sources. In this case, the average error relative to the amount of ionized molecules decreases with increasing ionization efficiency. This is in accordance with higher precision for APPI as compared to APCI.

For the use of the APPI-MS/MS method in biological matrix, incubations with lanosterol and $\mathrm{d}_{6}$-cholesterol were performed using a NADPH generating system and a human recombinant lanosterol demethylase (CYP51). With this method inhibitory activity of azoles on CYP51 could be determined (Figure 4). The quantitation of FF-MAS in supernatants of incubations shows clearly that the baculovirus expressed CYP51 forms FF-MAS with a similar turnover number of $0.1 \mathrm{pmol}$
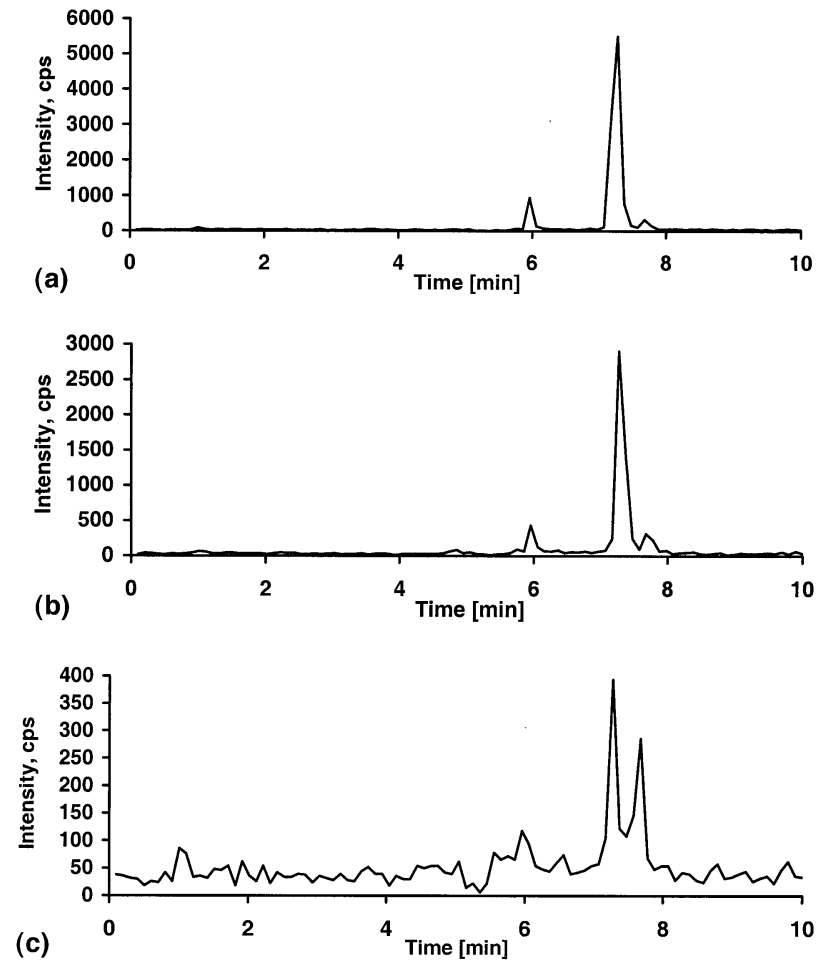

Figure 4. Separations of FF-MAS in incubations of lanosterol with CYP51 performed with different concentrations of epoxiconazole as inhibitor of CYP51 (a) $0.01 \mu \mathrm{M}$; (b) $3 \mu \mathrm{M}$; (c) $100 \mu \mathrm{M}$ ).

product/min $\times$ pmol protein as seen with an assay using $\left[{ }^{3} \mathrm{H}\right]$-lanosterol (data not shown).

To perform inhibition experiments of CYP51 by azoles a low LOQ and a wide dynamic range for FF-MAS is required to get suitable data to calculate $\mathrm{IC}_{50}$ values of azole derivatives. The concentrations of FFMAS were in a dynamic range of 1 to $10,000 \mathrm{ng} / \mathrm{ml}$ for FF-MAS determined by calibration curves. Only the ratio of the peak areas of FF-MAS and $\mathrm{d}_{6}$-cholesterol (= relative peak area) were used for calculation of $\mathrm{IC}_{50}$ values. This was possible, since a linear correlation between relative areas and concentration could be proven by the measurement of calibration curves $(n=3)$.

Due to the structural similarity of lanosterol with FF-MAS a completely resolved separation by HPLC of the analytes was not achieved. However, an unequivocal distinction of both substances was possible taking advantage of the specificity of the triple quadrupole mass spectrometer as detector since the characteristic MRM transitions are different for FF-MAS, lanosterol and $\mathrm{d}_{6}$-cholesterol. With the presented LC-APPIMS/MS method the sterols have to be separated only from buffer salts used in incubations due to the suppression of ionization by such high buffer concentrations. This results in short run times of $<10 \mathrm{~min}$ compared with HPLC-UV separations. When high concentrations of one analyte were injected, the two other substances were not detectable, clearly demonstrating that no artefacts were formed during the ionization process and that the standards were pure. A matrix 
effect that resulted in a reduction of peak areas was not observed. In connection with a well plate autosampler a fully automated assay with high sample throughput will be possible.

Due to its sensitivity, the method is not only applicable for the described assay using recombinant CYP51 but also for biological systems with lower CYP51 activity e.g., in microsomes or fungi. Furthermore, no expensive radioactive substrate is needed to perform this assay and analytes may be quantitated in every kind of sample like blood or urine. The LC-APPI-MS/MS method should also be useful for other sterols which have to be quantitated i.e., in river water near sewage plants or pastures of cattle for ecotoxicological risk assessments of a putative endocrine disrupting potential.

\section{Acknowledgments}

The statistical procedure was developed by R.W. Lutz of the Seminar for Statistics, Swiss Federal Institute of Technology, Zurich, Switzerland, in connection with the analysis of the inhibition of CYP19. This work was supported by the Swiss Federal Office of Public Health (grants 02.001534 and 03.001059)

\section{References}

1. Andersen, H. R.; Vinggaard, A. M.; Rasmussen, T. H.; Gjermandsen, I. M.; Bonefeld-Jorgensen, E. C. Effects of Currently Used Pesticides in Assays for Estrogenicity, Androgenicity, and Aromatase Activity in Vitro. Toxicol. Appl. Pharmacol. 2002, 179, 1-12.

2. Lepesheva, G. I.; Virus, C.; Waterman, M. R. Conservation in the CYP51 Family. Role of the B' Helix/BC Loop and Helices F and G in Enzymatic Function. Biochemistry 2003, 42, 9091-9101.

3. Pfaller, M. A.; Riley, J.; Koerner, T. Effects of Terconazole and Other Azole Antifungal Agents on the Sterol and Carbohydrate Composition of Candida albicans. Diagnos. Microbiol. Infect. Dis. 1990, 13, 31-35.

4. Majdic, G.; Parvinen, M.; Bellamine, A.; Harwood, H. J., Jr.; $\mathrm{Ku}, \mathrm{W}$. W.; Waterman, M. R.; Rozman, D. Lanosterol $14 \alpha-$ Demethylase (CYP51), NADPH-Cytochrome P450 Reductase and Squalene Synthase in Spermatogenesis: Late Spermatids of the Rat Express Proteins Needed to Synthesize Follicular Fluid Meiosis Activating Sterol. J. Endocrinol. 2000, 166, 463-474.

5. Cotman, M.; Jezek, D.; Fon Tacer, K.; Frangez, R.; Rozman, D. A Functional Cytochrome P450 Lanosterol $14 \alpha$-Demethylase CYP51 Enzyme in the Acrosome: Transport Through the Golgi and Synthesis of Meiosis Activating Sterols. > Endocrinology 2004, 145, 1419-1426.

6. Zarn, J. A.; Bruschweiler, B. J.; Schlatter, J. R. Azole Fungicides Affect Mammalian Steroidogenesis by Inhibiting Sterol $14 \alpha-$ Demethylase and Aromatase. Environ. Health Perspect. 2003, 111, 255-262.

7. Bellamine, A.; Mangla, A. T.; Nes, W. D.; Waterman, M. R. Characterization and Catalytic Properties of the Sterol $14 \alpha-$ Demethylase from Mycobacterium tuberculosis. Proc. Natl. Acad. Sci. U.S.A. 1999, 96, 8937-8942.

8. Lamb, D. C.; Fowler, K.; Kieser, T.; Manning, N.; Podust, L. M.; Waterman, M. R.; Kelly, D. E.; Kelly, S. L. Sterol $14 \alpha$-Demethylase Activity in Streptomyces coelicolor A3(2) is Associated with an Unusual Member of the CYP51 Gene Family. Biochem. J. 2002, 364, 555-562.

9. Baltsen, M.; Byskov, A. G. Quantitation of Meiosis Activating Sterols in Human Follicular Fluid Using HPLC and Photodiode Array Detection. Biomed. Chromatogr. 1999, 13, 382-388.
10. Razzazi-Fazeli, E.; Kleineisen, S.; Luf, W. Determination of Cholesterol Oxides in Processed Food Using High-Performance Liquid Chromatography-Mass Spectrometry with Atmospheric Pressure Chemical Ionization. J. Chromatogr. A 2000, 896, 321-334.

11. Nitahara, Y.; Aoyama, Y.; Horiuchi, T.; Noshiro, M.; Yoshida, Y. Purification and Characterization of Rat Sterol 14-Demethylase P450 (CYP51) Expressed in Escherichia coli. J. Biochem. 1999, 126, 927-933.

12. Penman, B. W.; Crespi, C. L. Analysis of Human Lymphoblast Mutation Assays by Using Historical Negative Control Data Bases. Environ. Mol. Mutagen. 1987, 10, 35-60.

13. Stromstedt, M.; Rozman, D.; Waterman, M. R. The Ubiquitously Expressed Human CYP51 Encodes Lanosterol 14 $\alpha$ Demethylase, a Cytochrome P450 Whose Expression is Regulated by Oxysterols. Arch. Biochem. Biophys. 1996, 329, 73-81.

14. Hashimoto, F.; Hayashi, H. Identification of Intermediates after Inhibition of Cholesterol Synthesis by Aminotriazole Treatment in Vivo. Biochim. Biophys. Acta 1991, 1086(115), 124.

15. Shyadehi, A. Z.; Lamb, D. C.; Kelly, S. L.; Kelly, D. E.; Schunck, W. H.; Wright, J. N.; Corina, D.; Akhtar, M. The Mechanism of the Acyl-Carbon Bond Cleavage Reaction Catalyzed by Recombinant Sterol $14 \alpha$-Demethylase of Candida albicans (Other Names are: Lanosterol $14 \alpha$-Demethylase, P-45014DM, and CYP51). J. Biol. Chem. 1996, 271, 12445-12450.

16. Desbrow, C.; Routledge, E. J.; Brighty, G. C.; Sumpter, J. P.; Waldock, M. Identification of Estrogenic Chemicals in STW Effluent 1. Chemical Fractionation and In Vitro Biological Screening. Environ. Sci. Technol. 1998, 32, 1549-1558.

17. Singh, G.; Gutierrez, A.; Xu, K.; Blair, I. A. Liquid Chromatography/Electron Capture Atmospheric Pressure Chemical Ionization/Mass Spectrometry: Analysis of Pentafluorobenzyl Derivatives of Biomolecules and Drugs in the Attomole Range. Anal. Chem. 2000, 72, 3007-3013.

18. Higashi, T.; Takido, N.; Yamauchi, A.; Shimada, K. ElectronCapturing Derivatization of Neutral Steroids for Increasing Sensitivity in Liquid Chromatography/Negative Atmospheric Pressure Chemical Ionization-Mass Spectrometry. Anal. Sci. 2002, 18, 1301-1307.

19. Greig, M.; Bolanos, B.; Quenzer, T.; Bylund, J. M. R. Fourier Transform Ion Cyclotron Resonance Mass Spectrometry Using Atmospheric Pressure Photoionization for High-Resolution Analyses of Corticosteroids. Rapid Commun. Mass Spectrom. 2003, 17, 2763-2768.

20. Robb, D. B.; Covey, T. R.; Bruins, A. P. Atmospheric Pressure Photoionization: An Ionization Method for Liquid Chromatography-Mass Spectrometry. Anal. Chem. 2000, 72, 3653-3659.

21. Byskov, A. G.; Andersen, C. Y.; Nordholm, L.; Thogersen, H.; Xia, G.; Wassmann, O.; Andersen, J. V.; Guddal, E.; Roed, T. Chemical Structure of Sterols that Activate Oocyte Meiosis. Nature 1995, 374, 559-562.

22. Nassar, A. E.; Varshney, N.; Getek, T.; Cheng, L. Quantitative Analysis of Hydrocortisone in Human Urine Using a HighPerformance Liquid Chromatographic-Tandem Mass Spectrometric-Atmospheric-Pressure Chemical Ionization Method. J. Chromatogr. Sci. 2001, 39, 59-64.

23. Peng, S. X.; Barbone, A. G.; Ritchie, D. M. High-Throughput Cytochrome P450 Inhibition Assays by Ultrafast Gradient Liquid Chromatography with Tandem Mass Spectrometry Using Monolithic Columns. Rapid Commun. Mass Spectrom. 2003, 17, 509-518.

24. Headley, J. V.; Peru, K. M.; Verma, B.; Robarts, R. D. Mass Spectrometric Determination of Ergosterol in a Prairie Natural Wetland. J. Chromatogr. A. 2002, 958, 149-156.

25. Joos, P. E.; Van Ryckeghem, M. Liquid ChromatographyTandem Mass Spectrometry of Some Anabolic Steroids. Anal. Chem. 1999, 71, 4701-4710. 